\title{
The Concept of Creating and Designing of Overview Digital Hydrological Atlas Maps within the GIS Project
}

\author{
Nikola STAMENKOVIĆ, Saša BAKRAČ, Miodrag KOSTIĆ, Svetislav ŠOŠKIĆ, Zoran SRDIĆ
}

\begin{abstract}
The paper presents the possibility of drafting and modelling of a part of geographic content of four overview atlas maps of Digital Hydrological Atlas of Serbia (DHAS), scale 1: 5000000 by using available open access cartographic sources and data, and applying cartographic methods and established steps of GIS digitization. The mapping territory and the approximate DHAS structure have been defined in the paper, as well as the mathematical elements of the overview atlas maps. A way of obtaining new modified overview atlas maps through the GIS integration of various cartographic data representing a part of the territory of the continent of Europe has been presented. The advantages of contemporary cartographic and GIS systems for modelling digital atlases and thematic hydrological atlas maps have been explained.
\end{abstract}

Keywords: digital hydrological maps; geographic information systems; Hydrological Atlas of Serbia; overview atlas maps

\section{INTRODUCTION}

The current level of development of geoinformation technologies and the opportunities provided by modern computer-supported cartography and geographic information systems (GIS) have enabled development of complex thematic and overview atlas maps in a new and modern way, which implies editing, analysis, processing and integration of different types and forms of cartographic data in the GIS environment. Considering the fact that currently the territory of the Republic of Serbia and the Balkan Peninsula do not have a hydrological atlas, which would process and display the entire geographic and hydrological content of the territory of Serbia in the region of the Balkan Peninsula and the European continent, the paper applies and evaluates already existing international practical and theoretical scientific knowledge concerning the development of modern digital thematic atlases [1, 2].The information and data from the official homepages of the Hydrological Atlas of Germany [3] and the Hydrological Atlas of Switzerland [4] concerning the methods of creating modern atlases were also considered and used.

Also, for compiling trial (test) version of the four maps of the Digital Hydrological Atlas of Serbia (DHAS), scale 1: 5000 000, appropriate professional and technical articles and foreign sources have been used in the paper [5-7], primarily those that are the product of official and authorized cartographic, geodetic and hydrographic services, organizations and agencies, whose activity is also the engagement in similar studies $[8,9]$.

\section{METHODOLOGY}

The main problems that had to be solved were processing, integration and adequate GIS representation of different types of vector and raster data that were available for the production of DHAS maps. Today, over sixty reference ellipsoids, as well as more than a hundred geodetic data and a large number of different cartographic projections are still in use for the production of various cartographic products [10]. Taking into account that the geographic and cartographic data, which were used in this paper through the open access sources, are available with variously defined mathematical data elements, it was necessary to process and adjust them in order to create hydrological overview atlas maps, scale 1: 5000000 . In order to define the territory of DHAS mapping, determine mathematical elements of the overview atlas maps and create a trial (test) version of the four maps, cartographic method, modelling method, comparative method, as well as the systems of methods of digitizing phenomena and processes (vectorization and rasterization) were used in the paper.

\section{DIGITAL HYDROLOGICAL ATLAS OF SERBIA - THE TERRITORY OF MAPPING}

Digital hydrological atlases or atlases of hydrological phenomena as a relatively new kind of atlases, which emerged in the second half of the twentieth and early twenty-first century can be defined as thematic and spatiosystemic atlases [11]. In this sense, DHAS would have the following territorial mapping areas:

- basic mapping territory (core), which would in principle be delineated by the state border line of the Republic of Serbia,

- closer outer territory of mapping (closer environment - the Balkans) and

- $\quad$ wider outer territory of mapping (wider environment the continent of Europe).

The basic mapping territory and the outer territories of the neighbouring environment in terms of distribution of hydrological phenomena, as content of a hydrological atlas, are not always clearly defined. The components of the core territory, that is, the geographic content of the basic territory of hydrological atlas is greatly influenced by processes and phenomena of the closer and wider geographic environment.

Digital Hydrological Atlas of Serbia would belong to a group of complex thematic atlases and would primarily present natural, physical and geographical phenomena. With its diversity and content, this atlas could provide maps of different purposes and appropriate data for a wide range of users, but also for specialists and experts in various fields. One of the goals of the cartographic DHAS 
project is to present geographic content of individual maps of hydrological atlas in digital GIS based concept.

\section{THE STRUCTURE OF THE ATLAS AND DEFINITION OF MATHEMATICAL ELEMENTS OF OVERVIEW ATLAS MAPS}

Taking into account the connectivity and complexity of hydrological phenomena and processes with other geographic phenomena (morphological structure of the terrain, geological structure, climatic elements, etc.), which directly or indirectly affect their mutual development, the structure of the complex DHAS is presented in individual chapters (titles) and currently there are seven proposed. In a separate chapter, there are spatial-systematic, overview maps and base maps of the atlas with scales of 1: 2000000 and 1: 5000000 . The remaining six chapters would consist of primary atlas maps (with a scale 1: 1500 000) that cover the territory of Serbia with a closer border zone, and they are: maps of surface hydrological phenomena and objects, maps of underground hydrological phenomena and objects, climatological and meteorological maps, maps of water balance, special thematic hydrological maps and environmental maps.

Within DHAS much of the content of the atlas maps is compiled, tentatively speaking, according to the system of derived maps in three main scales. In this sense, the borders of the mapping territory (Fig. 1) which are different for each type of the atlas map, would include in principle the following:

positional maps, general maps, overview maps, and spatial-systemic maps, scale $1: 5000000$, the territory between meridians $\lambda_{\mathrm{W}}=020^{\circ} 00^{\prime} 00^{\prime \prime}$ and $\lambda_{\mathrm{E}}=060^{\circ} 00^{\prime}$ $00^{\prime \prime}$ and parallels $\varphi_{\mathrm{N} 1}=30^{\circ} 00^{\prime} 00^{\prime \prime}$ and $\varphi_{\mathrm{N} 2}=70^{\circ} 00^{\prime}$ $00 "$ ",

- for general and overview-topographic maps scale $1: 2000000$, the territory between meridians $\lambda_{\mathrm{E} 1}=$ $012^{\circ} 00^{\prime} 00^{\prime \prime}$ and $\lambda_{\mathrm{E} 2}=030^{\circ} 00^{\prime} 00^{\prime \prime}$ and between parallels $\varphi_{\mathrm{N} 1}=36^{\circ} 00^{\prime} 00^{\prime \prime}$ and $\varphi_{\mathrm{N} 2}=48^{\circ} 00^{\prime} 00^{\prime \prime}$, for primary - multipage maps scale 1:1500 000, territory between $\lambda_{\mathrm{E} 1}=018^{\circ} 00^{\prime} 00^{\prime \prime}$ and $\lambda_{\mathrm{E} 2}=024^{\circ} 00^{\prime}$ $00^{\prime \prime}$ and between the parallels $\varphi_{\mathrm{N} 1}=41^{\circ} 30^{\prime} 00^{\prime \prime}$ and $\varphi_{\mathrm{N} 2}$ $=46^{\circ} 30^{\prime} 00^{\prime \prime}$.

In respect to differentiation of general purpose geographic maps according to their scale, overview DHAS maps belong to a group of small scale maps on which it is possible to display in more detail specific hydrological map content, whereas in respect to the categorization of atlas maps, they would belong to a group of spatial-systemic maps. In addition to the scale of atlas maps, it is necessary to determine the entire mathematical basis i.e. other mathematical elements of overview atlas maps. As for the geodetic basis of the overview atlas DHAS maps, they would be compiled on the basis and according to the parameters of a reference rotating ellipsoid or "geodetic datum" WGS84.

For overview and other DHAS maps scale $1: 5000000$ the Conformal Mercator Cylindrical Projection of intersecting parallel is proposed, and all other Atlas maps scale 1:2000000 and larger could be compiled in the Transverse Mercator Projection or the Lambert Conic Conformal Projection with two standard parallels. Thus, all DHAS atlas maps scale 1:5000 000 would be compiled in the Conformal Mercator Projection on a cylinder intersecting the WGS84 ellipsoid on the selected parallel. The cartographic network of map sheets of the proposed scale was calculated at the appropriate intersecting parallel i.e. the constructional latitude of true scale $\varphi_{\mathrm{K}}=50^{\circ} 00^{\prime} 00^{\prime \prime}$ North latitude. As a rule, the latitude of true scale $\varphi_{\mathrm{K}}$ of a single map sheet is calculated according to its medium or one of its close parallels, but the application of this rule may result in minor deviations.

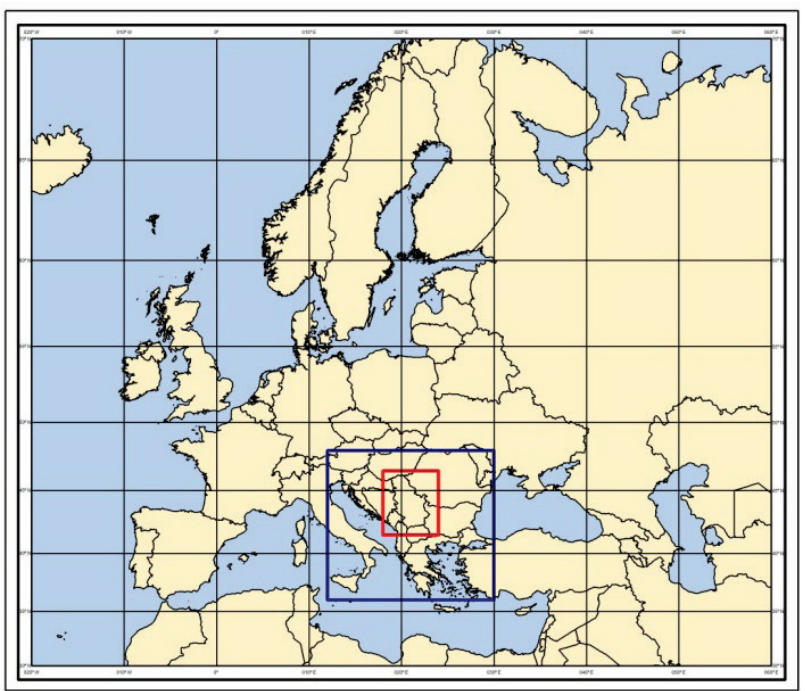

Figure 1 Presentation of internal frame relations of proposed atlas map scales of DHAS (black inside box - scale 1: 5000 000, blue box - 1: 2000000 and red box 1: 1500 000).

Prior to determining the final latitude of true scale for overview atlas maps, an analysis and calculations for a number of possible solutions were made, and the selected solution was optimal in terms of the size of usable map format, geographic location of the territory of Serbia and the Balkan Peninsula and possible deformations of the presented surface which would include traditional paper thematic maps at certain latitudes. Some possible solutions of dimensions of useful frame of overview maps with latitudes are shown in Tab. 1.

In Mercator Projection, similarity of infinitely small figures was preserved, and in this projection meridians and parallels were presented as directions that intersect at right angles, making a cartographic grid. Essentially, the very system of a projected cartographic grid makes the mathematical basis on which all overview hydrological atlas maps were compiled. The cartographic grid was drawn for every 5 degrees in terms of latitude and 10 degrees of longitude, which contributes to the aesthetic appearance and also enables easy orientation on the map (Fig. 2).

Dimensions of the useful (internal) format are marked on the maps in the lower right corner beyond the map frame $(1147.1 \times 972.0 \mathrm{~mm})$. For presenting the territory of the European continent on one sheet of a specific format (extended A0 format, or extended-joined A1 format) the optimal scale was selected. Approximate size of the mapping territory on overview atlas maps is relatively large and presents $5,735.65 \times 4,860.25 \mathrm{~km}$, which produces the biggest difference in the scale factor values from the maintrue scale and the scale at the final parallels, but there is no 
significant negative effect on the original and other possible purposes of the map and its appropriate practical use.

Table 1 Possible latitudes of true scale $\left(\varphi_{\mathrm{K}}\right)$ of overview DHAS atlas maps and dimensions of potential useful frames in Mercator Projection.

\begin{tabular}{|c|c|c|c|c|}
\hline \multirow{2}{*}{$\begin{array}{c}\varphi_{\mathrm{K}} \\
\text { (degrees) }\end{array}$} & $\begin{array}{c}\text { Dimensions of useful map } \\
\text { format } \\
(\mathrm{mm})\end{array}$ & $\begin{array}{c}\text { Distance of } \\
\varphi_{\mathrm{K}} \text { from the } \\
\text { north (N) map } \\
\text { border (mm) }\end{array}$ & $\begin{array}{c}\text { Distance of } \\
\varphi_{\mathrm{K}} \text { from the } \\
\text { medium } \\
\text { parallel }-\varphi_{\mathrm{SR}} \\
(\mathrm{mm})\end{array}$ \\
\hline 45 & 1261.5 & 1069.0 & 770.2 & 235.7 \\
\hline 46 & 1239.4 & 1050.2 & 734.7 & 209.6 \\
\hline 47 & 1216.9 & 1031.2 & 699.3 & 183.7 \\
\hline 48 & 1194.0 & 1011.8 & 664.1 & 158.2 \\
\hline 49 & 1170.7 & 992.1 & 629.2 & 133.1 \\
\hline 50 & 1147.1 & 972.0 & 594.5 & 108.4 \\
\hline 51 & 1123.2 & 951.7 & 560.0 & 84.2 \\
\hline 52 & 1098.8 & 931.1 & 525.9 & 60.3 \\
\hline 53 & 1074.2 & 910.2 & 492.1 & 37.0 \\
\hline 54 & 1049.2 & 889.1 & 458.6 & 14.1 \\
\hline 55 & 1023.9 & 867.6 & 425.6 & 8.2 \\
\hline
\end{tabular}

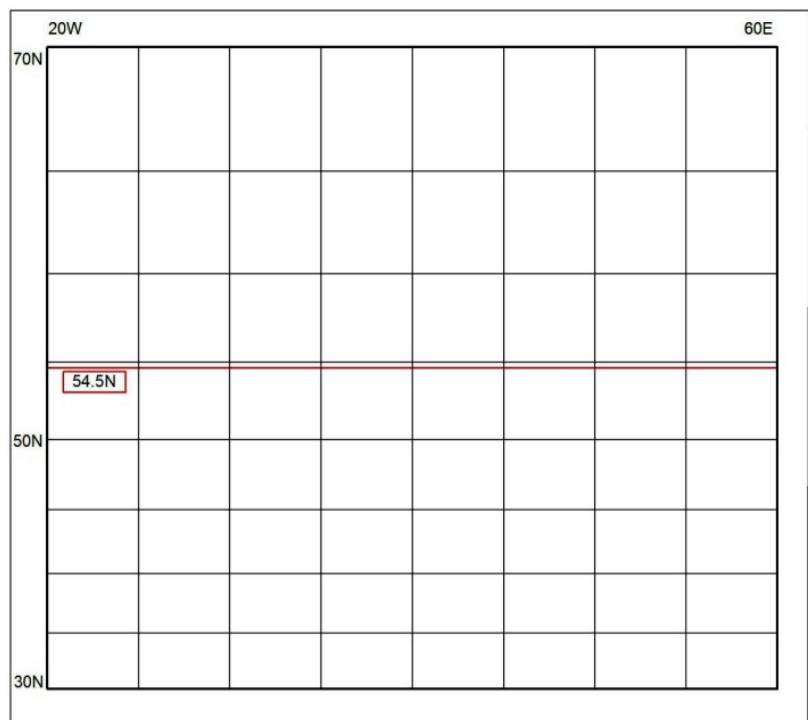

Figure 2 Appearance of a map grid of DHAS overview maps in the Mercator Projection $\left(\varphi_{\mathrm{K}}=50^{\circ} \mathrm{N}\right.$ and $\left.\varphi_{\mathrm{SR}} \approx 54,5^{\circ} \mathrm{N}\right)$.

The territory of Serbia and the Balkan Peninsula is presented in the central southern part of the map field (Fig. 1), and linear scale factor in this part of the map that covers the territory of the Balkan Peninsula is approximately $1: 5500000$ (Tab. 2). Also, Tab. 2 shows the coefficients of the scale in the Mercator Projection on the latitude of true scale and selected arbitrary parallels (latitudes) of the map. To define mathematical basis of the overview atlas maps, automated and computer-supported method for calculating mathematical elements in the GIS environment was used. Within Intergraf's GIS software GeoMedia Professional and Windows operating software, the socalled operating geoworkspace was defined with parameters of the Mercator Projection and other previously mentioned mathematical elements [12]. The geoworkspace, which was also used for cartographic presentation of spatial phenomena, was linked to the new database within the same software programme. Identical mathematical elements for the overview atlas maps were also determined because of the data consistency. The appropriate map grids of meridians and parallels were drawn in Mercator Projection and were stored in two ways: as a separate layer of data with the defined legend in a selected operating geoworkspace (special cartographic page) and in the form of raw data sets in a database of spatial data. The GIS software allows the highest accuracy of data sets stored in the database to be one centimetre. A coordinate system file was defined and stored on a computer with parameters of Mercator Projection within the software and the extension .csf, which can also be used when mathematical parameters of other necessary geoworkspaces for compilation of overview atlas maps are to be defined.

Table 2 Main scale and ratio coefficients in Mercator Projection on the latitude of true scale $\varphi_{\mathrm{K}}=50.0^{\circ}$ and selected arbitrary parallels of an overview map of DHAS, scale 1: 5000000.

\begin{tabular}{|c|c|c|c|c|}
\hline $\begin{array}{c}\text { Parallels } \\
\left(\varphi^{\circ}\right)\end{array}$ & $\begin{array}{c}\text { Main scale } \\
(\mathrm{M})\end{array}$ & $\begin{array}{c}\text { Scalefactor } \\
\text { at other } \varphi \\
(\mathrm{C}) \\
\text { (approx.) }\end{array}$ & $\begin{array}{c}\text { Ratio } \\
\text { coefficient of } \\
\text { linear } \\
\text { deformation }\end{array}$ & $\begin{array}{c}\text { Ratio } \\
\text { coefficient of } \\
\text { surface } \\
\text { deformation }\end{array}$ \\
\hline$\varphi=30$ & $1: 5000000$ & $1: 6736481$ & 1,347 & 1,814 \\
\hline$\varphi=40$ & $1: 5000000$ & $1: 5958768$ & 1,192 & 1,421 \\
\hline$\varphi=45$ & $1: 5000000$ & $1: 5500314$ & 1,100 & 1,210 \\
\hline$\varphi_{\mathrm{K}}=50$ & $1: 5000000$ & $1: 5000000$ & 1,000 & 1,000 \\
\hline$\varphi=60$ & $1: 5000000$ & $1: 3889310$ & 0,778 & 0,605 \\
\hline$\varphi=70$ & $1: 5000000$ & $1: 2660444$ & 0,532 & 0,283 \\
\hline
\end{tabular}

The programme GeoMedia Professional provides a great number of options in terms of storage of geographic data in respect to different coordinate systems [12]. These coordinate systems provide a mathematical basis for presenting the established mutual relations of objects in terms of their actual position in nature. The software supports and recognizes three categories of coordinate systems that are referred to as:

- the projected coordinate systems (the option of selecting different types of projections, ellipsoids, geodetic data, units of measurement, errors, etc.),

- geographic coordinate systems (coordinates defined as longitude and latitude - angles' size) and

- geocentric coordinate systems (geodetic coordinates defined with respect to the Earth's centre).

In all three categories, interpretation of coordinates in respect to the geodetic datum is possible, which precisely defines the reference ellipsoid and its position relative to the Earth's surface.

\section{CARTOGRAPHIC DATA SOURCES FOR THE COMPILATION OF THE OVERVIEW DHAS HYDROLOGICAL MAPS}

Currently, for purposes of trial compilation of a part of geographic content of overview hydrological atlas maps, in this paper the following basic and additional cartographic sources of various formats in analog and digital (raster and vector) form were used:

- data from the Shuttle Radar Topography MissionElevation Data Set - SRTM project $[13,14]$,

- data from The Advanced Spaceborne Thermal Emission and Reflection Radiometer-Global Digital Elevation Model - ASTER GDEM project [15],

- data from the Global Topographic 30 Arc Second Elevation Data - GTOPO30 project [16],

- data from the so-called HYDRO1k project; the United States Geological Survey and the National Center for 
Earth Resources Observation and Science - USGS EROS formed the geographic base of hydrological data with resolution of 1 kilometre [17],

cartographic material of the Military Geographical Institute Belgrade (MGI), that is, the International Map of the World, scale 1:1000 000 [18], and selected and limited geographic content of the General Geographic Map of FR Yugoslavia at a scale $1: 1000000$ [19], and data from the project The International Hydrogeological Map of Europe - IHME 1500, that is, selected and limited geographical content of individual sheets of International Hydrogeological Map of Europe, scale $1: 1500000$ [20].

In order to obtain additional information about the territory covered by the overview atlas maps and to compile and design some of the content of the overview atlas maps, numerous supplementary and additional sources such as open access internet sources were used. These were primarily: professional and research papers $[21,22]$ and official data of relevant national and international institutions and organizations, as well as international mapping and hydrological institutions and organizations. The basic categories that were taken into consideration were geometric accuracy, geographical precision and their contemporaneity.

\section{GEOGRAPHIC CONTENT OF THE OVERVIEW ATLAS MAPS}

In respect to the scale of individual groups of atlas maps and their category, geographic elements of atlas maps can be divided conditionally into four groups that are presented through the following contents: topographic, hydrological, geological and lithological and auxiliary informative. On all categories of atlas maps and overview atlas maps as well, the basic elements are presented: map grid (a grid of meridians and parallels on the overview maps) and part of the hydrographical network (river network).

Hydrological content is the primary part of the geographic content on hydrological land maps that is integrated with geological and possible thematic elements while fully respecting the additional verified information about the mapping territory. The main factors affecting the current selection of hydrological content of the overview atlas maps are available resources and appropriate data sources, existing conventions and legislation regulating this broad area, map scale, customer needs, hydrological projects that were realized in the relatively recent past (from the aspect of validity and durability of hydrological data), and parallel projects that are being realized. The main hydrological content i.e. primary hydrological elements of the overview and base hydrological atlas maps in this paper are: a river network of the continent of Europe and the Balkan Peninsula, watersheds and river basins and aquifers. In addition to these elements on the overview hydrological maps, a part of the hydrographic network of Europe and the Balkan peninsula which refers to lakes and less significant waterways is presented with the specific scale of the atlas maps.

\section{MODELLING OF THE OVERVIEW DHAS HYDROLOGICAL MAPS 7.1 GIS Preprocessing}

In this paper, the work on the structure of four overview DHAS atlas maps started, with previously defined mathematical elements and current editorial data. The structuring of the overview atlas maps indirectly depended on and was closely related to the most up-to-date way of making digital thematic maps and traditional cartographic method [23]. After a preliminary defining of the general structure of the hydrological atlas, division of the territory into the mapping sheets and defining of possible cartographic sources and basic mathematical elements of the overview DHAS atlas maps, the GIS preprocessing stage began. It precedes the cartographic modelling, data integration and representation of phenomena and processes that we want to introduce. Preprocessing in GIS involves processing and preparing of all external spatial databases, vector and raster, which can be used for the compilation of the overview DHAS atlas maps. Processing of available data refers to customizing and adapting of the form and data structures intended for use within the desired GIS software.

Different formats of source data that are used when creating DHAS, and different ways of collecting and processing within the existing information systems imply paying particular attention to the ways and forms in which the data, whether in raster or vector form, were stored and archived in the existing databases. Special attention should be paid to downloading and use of data on digital elevation models in various application software. Also, for most external databases, the coordinate system files with the extension .cfs were defined, within the additional module of the GeoMedia Professional GIS programme. The coordinate system file is materialized through a defined structure that GeoMedia uses to store information about the characteristics and values of certain mathematical elements of spatial data and maps from the databases that do not contain such information as internal.

For HYDRO1k part of the project, that covers the territory of the European continent, previously mentioned projection information and information on georeferencing were obtained, and a coordinate system file with the required file extension and an initial file in specially designated folders were designed. From the current operating geoworkspace of GeoMedia, a new open connection through the appropriate data server with HYDRO1k databases containing vector data on European water flows and basins (layers of data - ESRI shape files) was established. This provides an overview of data in the GIS GeoMedia software, but not the possibility of their editing. If we want to be able not only to browse the data, but to have unlimited access to all available external data and layers within the programme i.e. to be able to add new objects or to modify the respective attributes and geometry of the existing geographic objects, one of the ways is to create and name a new Access database. After creating the database and before its completion, several coordinate system files can be predefined in order to be used for the generation of a class of objects in the new Access database.

In the case of creating DHAS, previously defined mathematical elements of the Mercator Projection for the 
resolution of atlas maps of $1: 5000000$ scale were predefined. The newly created Access database, with an open connection in the existing operating geoworkspace of the GeoMedia, was completed with the desired ESRI shape files from the external database, which are now called classes of objects and can be named and edited (their attributes, geometry, names, projection, display can be changed). Similarly, with appropriate implementation of procedures and with essential knowledge and definition of the required values of the necessary parameters, it is possible to connect with other vector and external databases in the GIS GeoMediasoftware.

Some of the possible cartographic sources for compiling hydrological atlas maps, scale $1: 5000$ 000, are data in digital raster format from SRTM project, downloaded from the website Consultative Group for International Agriculture Research Consortium for Spatial Information - CGIAR CSI [13]. In this paper, among other things, a preliminary preparation of the four so-called "cells" of the SRTM digital elevation model supplied in $5^{\circ}$ $\times 5^{\circ}$ size in ASCII format was performed. They can also be downloaded in GeoTIFF format. The designations used for the cells are the following: srtm_40_03, srtm_40_04, srtm_41_03 and srtm_41_04. They cover a part of the territory of the Balkan Peninsula i.e. Serbia, (Fig. 3). Fig. 3 shows the preparation of data in GIS, which includes a number of well-established steps.

The size of the grid of a SRTM digital model corresponds to the value of 3 arc seconds, so that, generally speaking, the SRTM data at a global level are available in the declared 90-meter resolution. For the observed part of the mapping territory of the Balkan Peninsula actual resolution (the real size of a grid -distances on the Earth's surface) was calculated for all four previously defined cells, and on average, it is 65,45 meters. Respective average resolution of the cells, which were subsequently named as layers in GeoMedia amounts to: srtm_40_03 = $62,73 \mathrm{~m}$, srtm_40_04 $=68,43 \mathrm{~m}$, srtm_41_03=62,73 m, srtm_41_04 $=\overline{6} 8, \overline{43} \mathrm{~m}$.
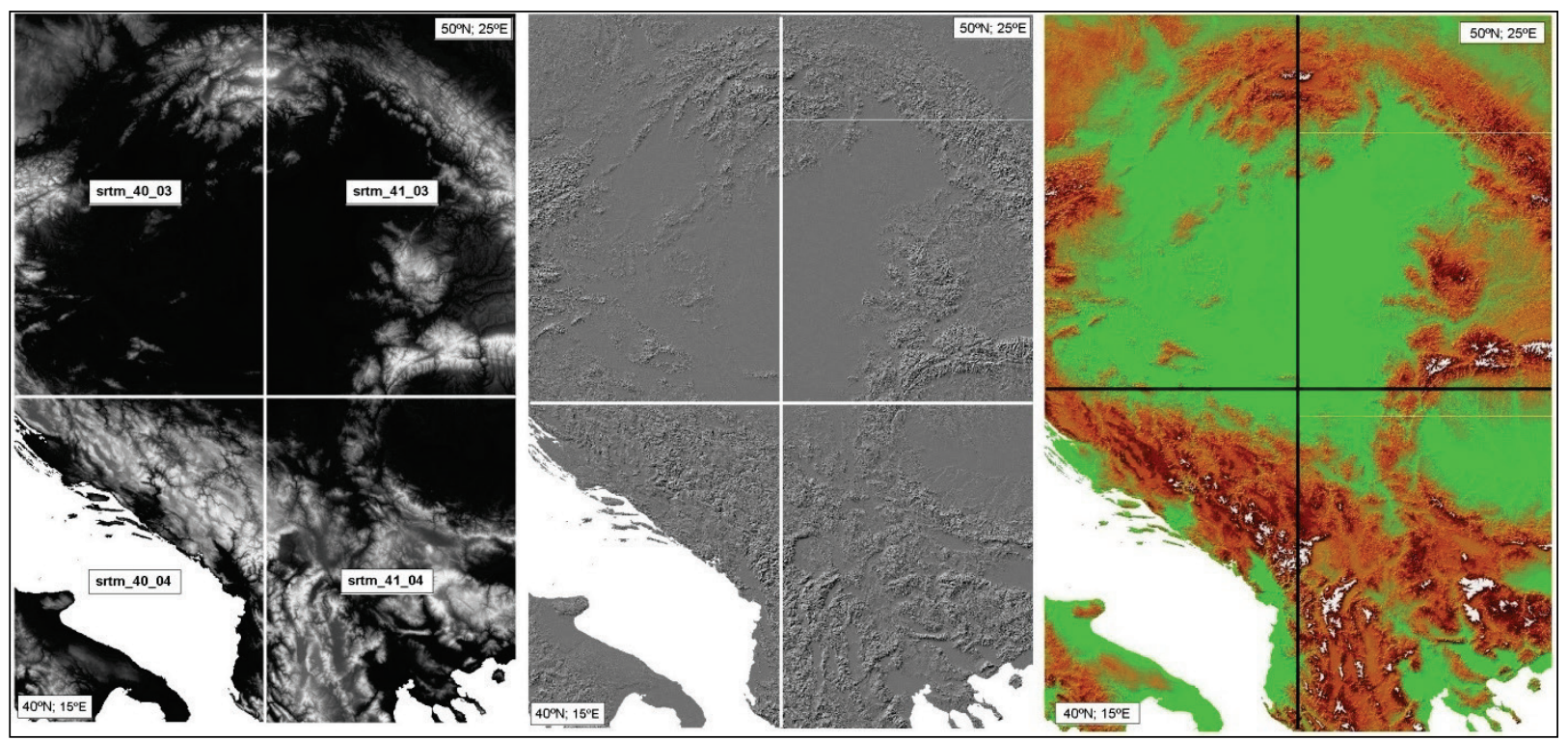

Figure 3 Reduced GIS raster layers from the SRTM project - a part of a digital elevation model of the Balkan Peninsula. In the figure, from left to right are shown: basic SRTM cells that were used, then the obtained digital shaded relief in grey scale tones and finally the obtained resultant raster layers from the SRTM project with classified and grouped values of the digital elevation model (DEM) and the assigned shades of colours.

For the preparation of the downloaded raster-grid files i.e. the previously mentioned cells in ASCII format, and for the purpose of the DHAS compilation, the additional GeoMedia Grid module was used. The use of this additional module was enabled because information on georeferencing was available i.e. it was possible to predefine the coordinate system file for the downloaded files of external data. From the current operating geoworkspace with defined parameter values of the Mercator Projection, a new Access database was created and designated, in which the so-called "field of study" for the grid files was established. The new "field of study" was named with a provisional name "Područje_1" (Area_1). Through the open connection with the new Access database and within the active area of study called "Područje_1", four grid files were imported into a geographic information system, which in GeoMedia actually became four layers - classes of objects that can be viewed, edited and analysed. Also, regardless of the original projection and coordinate system of the data stored in the Access database, GeoMedia automatically performs reprojection of all data stored in the database into a projection defined for the currently open operating geoworkspace.

Also, as a possible cartographic source for compilation of hydrological atlas maps, scale $1: 5000$ 000, a part of the geographic content of hydrogeological maps of the IHME 1500 series can be used. For purposes of this study, the following map sheets of the IHME 1500 series in raster format were used: D5 - Budapest, D6 - Athina, E5 Bucuresti and E6 - Ankara. Converted files of map sheets with new extensions .jpg and tif were stored in separate folders. One folder was used to store predefined coordinate system files of the selected IHME 1500 map sheets with parameter values of equidistant conic projection with two standard parallels. For many years of preparation of the IHME 1500 map sheets, designers and publishers of maps have taken the Bessel ellipsoid as the reference ellipsoid. 
With regard to the proposed scale of the overview atlas maps (1:5000 000) and obtained minimum error of about $0,1 \mathrm{~mm}$ in the scale of the map, that may appear during the georeferencing of the selected sheets of the IHME 1500 series, by using the values of the parameters of the satellite WGS84 datum, it was concluded that these errors ranged within the allowed limits. At a later stage of the modelling and structuring of the overview atlas maps, it is possible to do the new registration and transformation of raster data in order to reduce errors caused by using different geodetic data The viewing of these four maps was carried out within the GeoMedia programme by establishing the new operating geoworkspace and newly opened Access database and its connection that enabled referencing and importing from a directory of predefined coordinate system file of equidistant conic projection with the satellite WGS84 datum.

As in the earlier period of development and modelling of four overview DHAS maps i.e. during 2013 and early 2014, vector IHME 1500 data sheets did not exist in free form available for download and were not controlled by official international and domestic entities, but were available only in raster form. In this paper, a trial, standard "on screen" digitizing of only one part of the geographic content of those sheets was conducted. Operating GeoMedia geoworkspace can be tentatively seen as a single cartographic sheet on which already georeferenced IHME 1500 map sheets were imported (introduced).

Simultaneously with digitizing of specific geographic IHME 1500 content, its partial unification and generalization was performed. In order to integrate and present different data necessary for compilation of a hydrological atlas, and to shorten the needed long period required for digitizing extensive hydrological content and convert it into a vector form, tentative "merging" i.e. "enlargement" of the existing six types of aquifers resulting from IHME 1500 was performed. Three types of aquifers (Fig. 8) temporarily united in a test version were obtained. They were subsequently further processed and edited and were given the following conditional names:

- porous aquifers with some degree of permeability,

aquifers with particular permeability involving karst, and

aquifers with low permeability or layers with no groundwater.

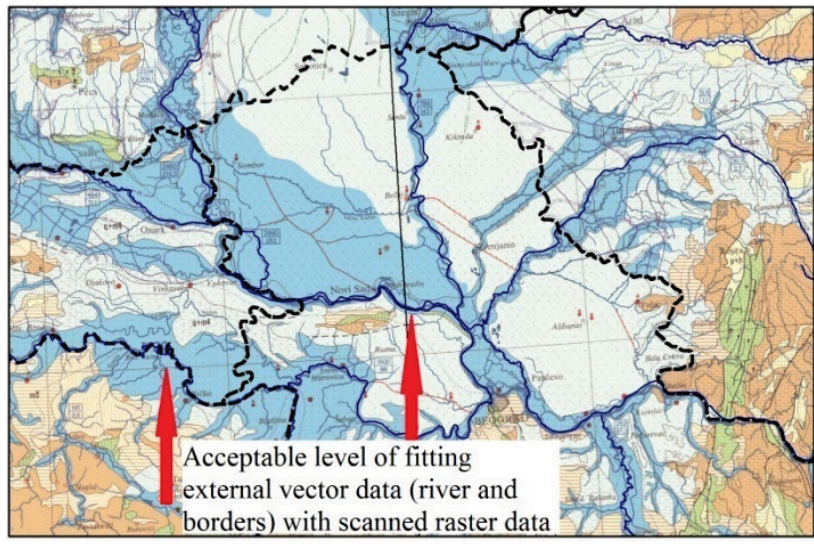

Figure 4 Example of an acceptable level of incorporation in the GIS of externa vector data with the georefenced raster map - Budapest D5 from IHME1500 Project (for operating geoworkspace in GIS, reference coordinate system file with values of the parameters of Equidistant Conic Projection was used)
Digitizing and overview of raster and vector data is performed in the geoworkspace of GIS in the primary projection in which the data were created (Fig. 4). Then copying and storing of the data in the new Access database was performed, with desired projection and the selected new mathematical elements of the database itself. In order to further review and edit data in the new database, it is necessary that the so-called cartographic page that we are currently compiling and working on and the Access database from which data are imported and which is in open connection with the sheet, all have identical mathematical elements i.e. coordinate system files.

\subsection{Data Integration and Structuring in GIS}

In this paper, a part of the geographic structure of the following overview atlas maps, scale $1: 5000000$ was developed and presented:

- Overview Hydrographic-geomorphological Map of Europe - PHKE_5000 (Fig. 5),

- Overview Map of the Relief Structures of Europe PKSE 5000 (Fig. 6),

- Overview Map of the Europe Basin - PKBE 5000

(Fig. 7) and

- Overview Map of Aquifers ofEurope - PKAE_5000

(Fig. 8).

During the testing phase and trial of integration and processing of various cartographic data in vector form that are used for the compilation of DHAS, identical parameters for the operating geoworkspace of GeoMedia and for certain classes of objects from the Access database were formed in terms of the identical values of the applied coordinate system file. Thus, for example, a replica of the vector part of the contents of the IHME 1500 sheets (previously obtained by digitizing) and stored under the GeoMedia in the Access database with the parameter values of the desired Mercator Projection was generated. In the same way, the data of other vector content (HYDRO1k, GTOPO30, etc.) were treated, and their overlapping and review by defining specific object classes. Raster data with the declared accuracy were imported into a defined GeoMedia geoworkspace and compared with the resultant vector, so some differences or similarities i.e. errors on the studied hydrological map content can be observed. Editing of integrated data of hydrological content of the overview atlas maps in GeoMedia operating geoworkspace also implied the removal and fine adjustment of certain hydrological content in respect to other geographic content. This was primarily related to the editing of quantity and types of hydrological content which was necessitated by the suggested scale of the overview atlas maps, scale $1: 5000000$.

Structuring of a part of the overview hydrographicgeomorphological map of Europe - PHKE 5000 (Fig. 5) implied and required access to data on elevation of the mapping territory, and knowledge of exact resolution of downloaded "raw" data. The next step involved preparation and review of these data, analysis and creating possible new data that are useful and exchangeable for further processing. Taking into account the fact that, on the one hand, greater generalization of data also means more productive content of the map, and on the other hand the 
assumption that for small scale maps a certain error for the vertical accuracy is allowed, a 32 bit digital elevation model in the format GeoMedia Grid with the extension of the raster file .mfm was obtained. Subsequently, it can be processed and adapted to further use. Forming of certain digital hydrological models and overview thematic maps of hydrological phenomena implies not only current design of certain maps in terms of allocation and application of appropriate map colours and shades or definition of line thickness, size, layout and type of letters and numbers, but also the overall consideration of the map display, its readability and mental impression that it can have on users. For these reasons, a specific hypsometric colour scale for PHKE_5000 elevation was proposed (Fig. 5).
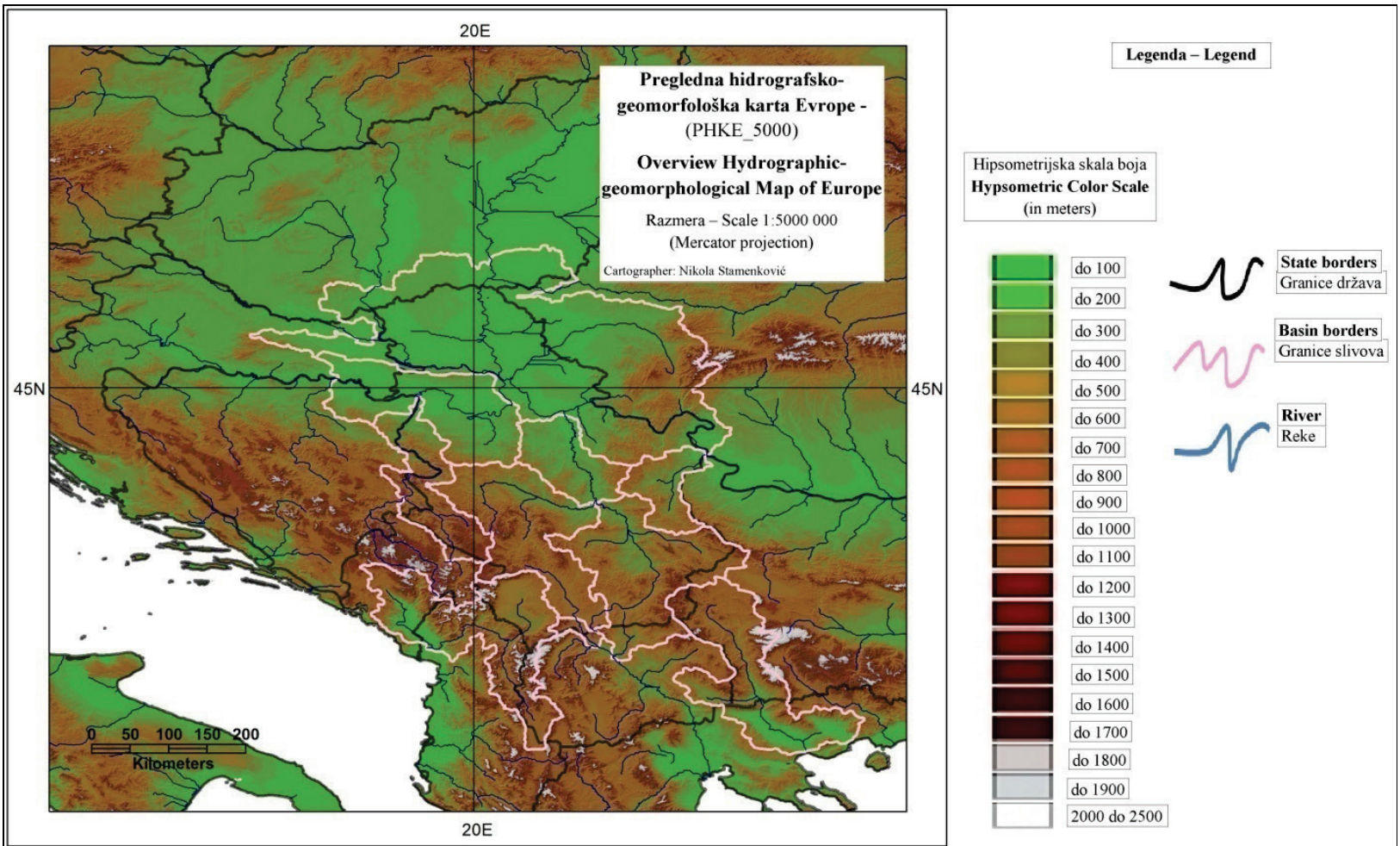

Figure 5 Reduced part of the PHKE_5000 working version. The picture shows a part of the geographic PHKE_5000 content i.e. the model-map shows a part of the Balkan Peninsula with certain approximate borders of the major river basins of Serbia.

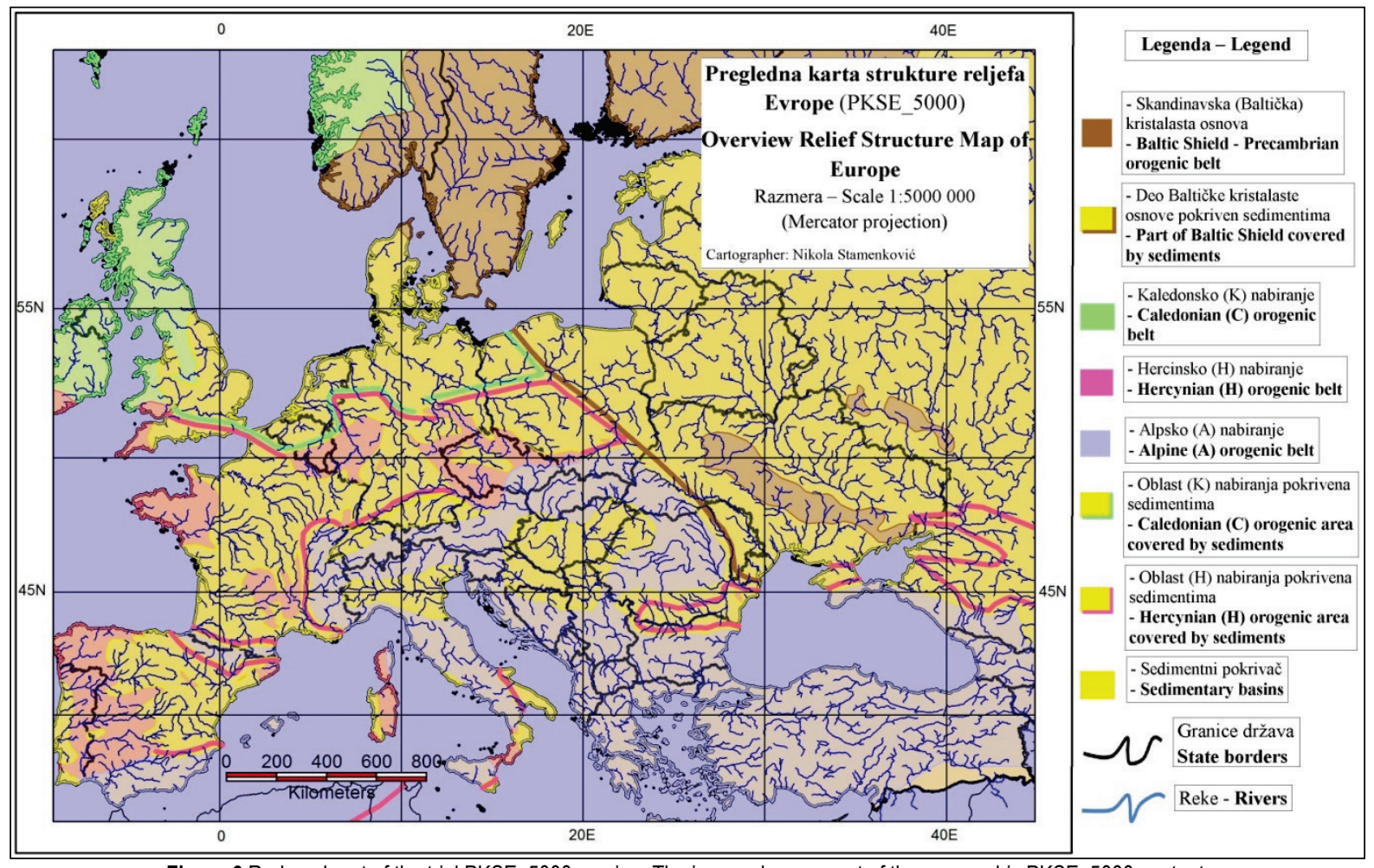

Figure 6 Reduced part of the trial PKSE_5000 version. The image shows a part of the geographic PKSE_5000 content. 
The overview map of the relief structures of Europe PKSE 5000 (Fig. 6), highlights the drainage network of the European continent in relation to large zones and areas of tectonic activity, while simultaneously presenting zones of sedimentary cover and crystalline Scandinavian base. On the object map, in the background, slightly shaded administrative borders of the European states are presented. Since the zones showing the structure of the relief of the European continent are determined and stored in a database as a kind of geometric polygon type, it is possible to perform graphics dissection of the displayed relief structure and possibly to assign new attributes later.

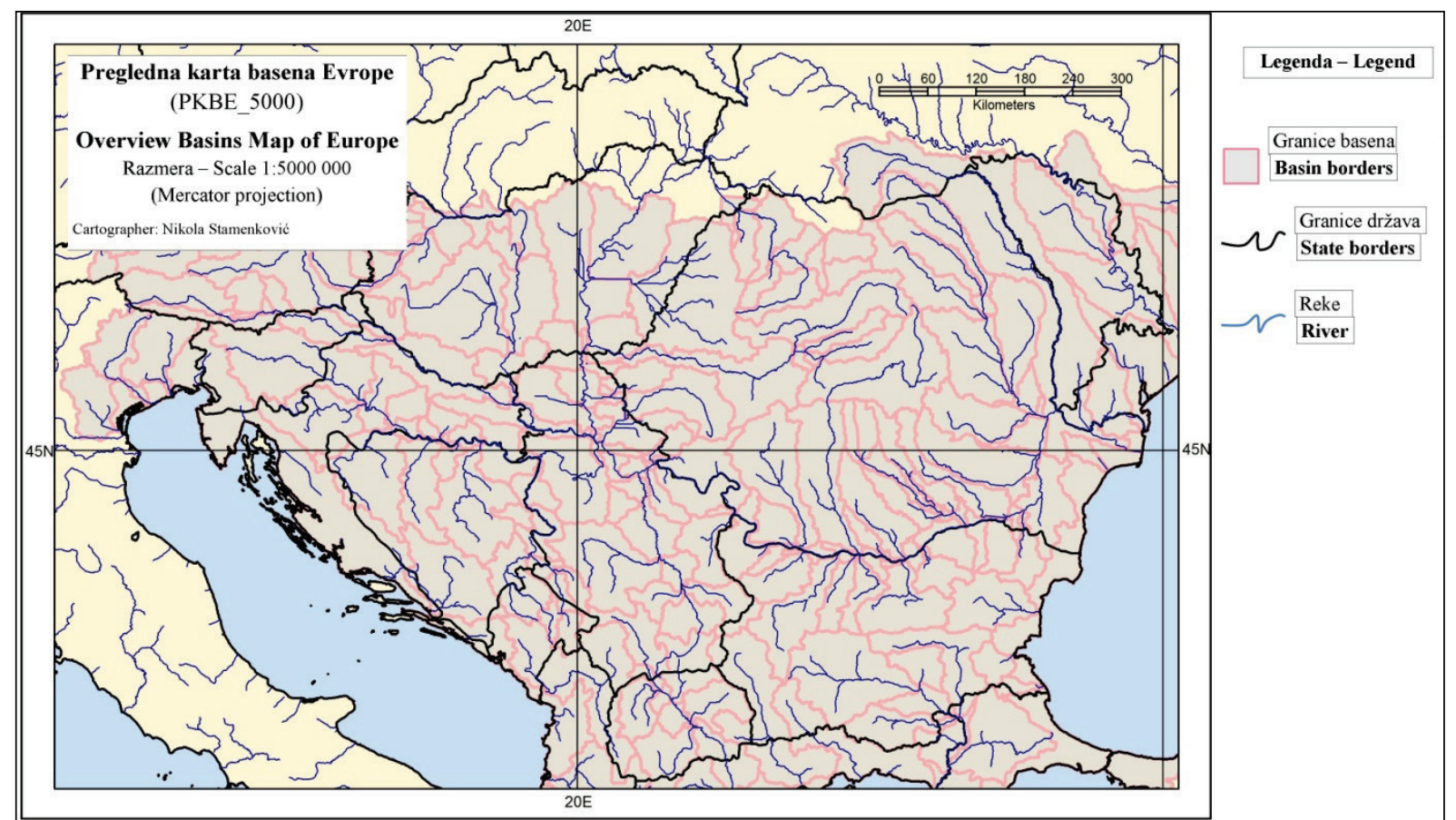

Figure 7 Reduced part of the trial PKBE_5000 version. The image shows a part of the geographic PKBE_5000 content, with approximately defined and displayed arranged borders of disaggregated basins of the Balkan peninsula (base HYDRO1k Project) in the vector data.

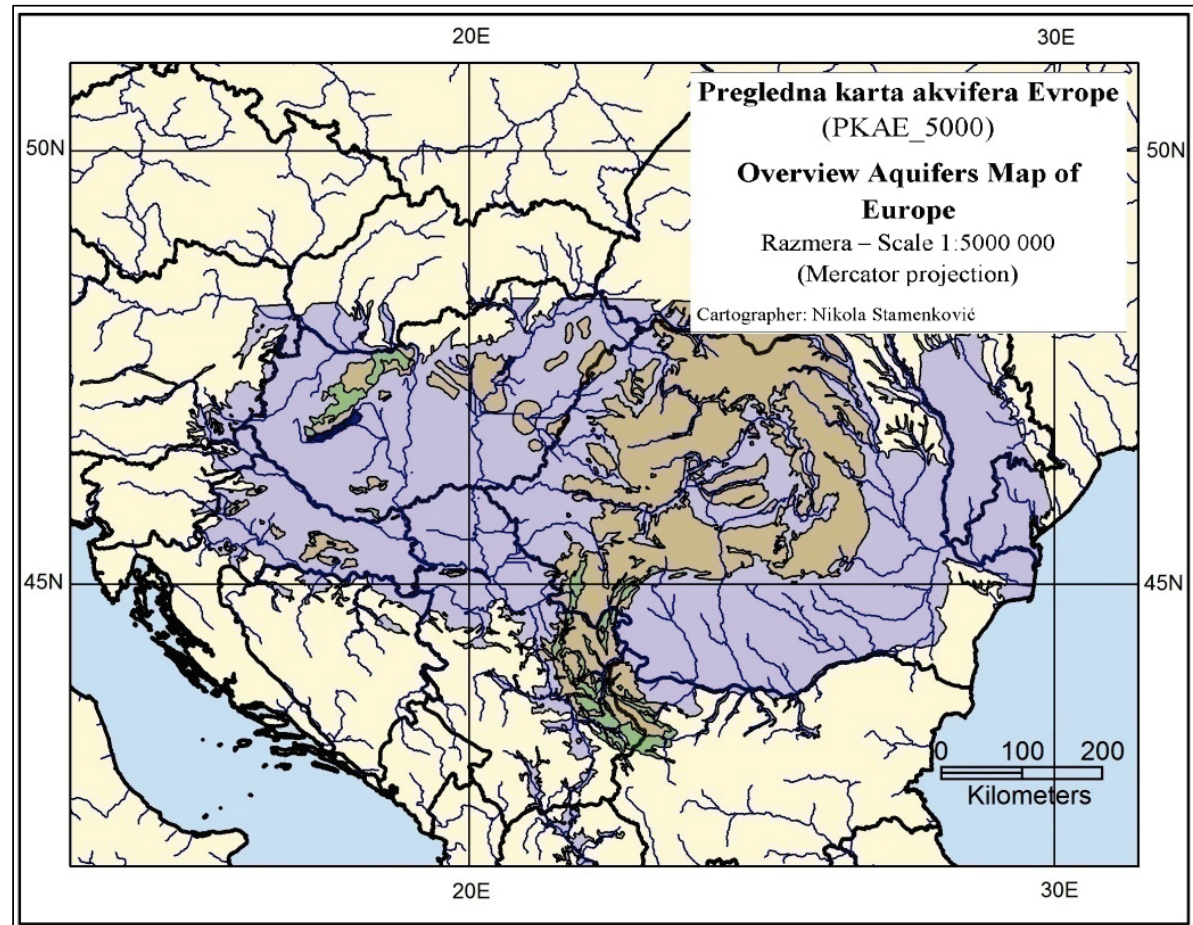

\section{Legenda - Legend \\ - Porozni akviferi sa određenim stepenom vodoprovodnosti \\ - Porous aquifers with a certain \\ degree of permeability}

- Akviferi sa odredenom vodoprovodnošću koji uključuju karst

- Aquifers with a specific permeability including karst

- Akviferi sa niskom

vodoprovodnošću ili slojevi bez podzemnih voda

- Aquifers with low

permeability or layers without

groundwater

\section{Granice država}

$\mathcal{\sim}$ State borders

Reke

Figure 8 Reduced part of a trial PKAE_5000 version. The image shows a part of the territory of South Eastern Europe and the Balkan Peninsula and the integration of a part of the digitized vector content from the IHME1500 project and with other processed cartographic sources in vector format.

Within the planned cartographic process we worked on the integration of various hydrological mapping data from multiple cartographic sources in order to study the possibilities of imbedding various hydrological content and forming a specific hydrological model of a territory for the required resolution or data for maps of $1: 5000000$ scale. Fig. 7 shows one of the possible ways of forming the overview thematic DHAS maps i.e. a hydrological model 
of a part of the territory of the continent of Europe based on geographic data from different projects. It is the formation of the overview map of the basin of Europe, scale 1:5000 000 (PKBE_5000) and modelling of the hydrological space of a part of the Balkan Peninsula, by overlapping in a specific order of the previously prepared cartographic vector layers presented in different methods of representation within the GIS software.

Also, for forming a working version of the overview map of the aquifers of Europe, scale 1:5000000 (PKAE_5000), and after the trial digitization of a part of the hydrological content of four raster maps from the IHME 1500 Project (Bern_C5, Budapest_D5, Bucuresti_E5 and Athina_D6), a particular merging of the obtained vector content (Fig. 8) with the other basic cartographic sources in vector format was performed.

\section{RESEARCH RESULTS}

In this paper, the synthesis of cartographic and GIS methods has been presented and as the final product of the cartographic process the formation of working versions of specific hydrological models (maps) and certain overview atlas maps. Four versions of digital overview hydrological atlas maps with specific geographic content (in raster or vector form) were produced within the framework of the proposed DHAS mapping project, on the basis of the proposed way of integration and development of hydrological maps in the GIS environment. In this particular case of DHAS, the results of similar studies and realized projects in the world were applied and appropriate resolutions of data for individual chapters and individual DHAS maps were proposed, while special attention was paid to research and determination of mathematical elements of the overview atlas maps i.e. models.

\section{CONCLUSION}

The paper presents the possibility of obtaining a part of geographic content of contemporary hydrological models - maps in a GIS environment i.e. phases of preprocessing, integration and structuring in GIS within the cartographic modelling were defined and proposed. They present multidisciplinary, closely related steps in the formation of hydrological models and overview atlas maps. Those steps are preceded by research, processing and approval of the necessary cartographic source data that are open and available for download in order to be used for research purposes. The obtained digital cartographic products in the scale of $1: 5000000$ have not been fully completed yet on the level of spatial database. Work on these draft (test) versions of hydrological maps continues and modelling of the remaining geographic content of the hydrological atlas maps of the Balkan Peninsula and Serbia also continues in accordance with the intended resolution.

\section{REFERENCES}

[1] Pucher, A., Kriz, K., \& Katzlberger, G. (2007). Atlas Information System of Austria. Proceedings of XXIII International Cartographic Conference. Moscow. Retrieved from http://icaci.org/files/documents/ICC_ proceedings/ ICC2007/documents/doc/THEME\%2015/Oral\%202/ATLA
S\%20INFORMATION\%20SYSTEM\%20OF\%20AUSTRI A.doc and from http://icaci.org/files/ documents/ICC_proceedings/ICC2007/html/Proceedings.ht $\mathrm{m} \# 15$

[2] Sieber, R., Hollenstein, L., Odden, B., \& Hurni, L. (2011). From Classic Atlas Design to Collaborative Platforms: The Swissatlasplatform Project. Proceedings of XXV International Cartographic Conference. Paris. Retrieved from https://www.atlasderschweiz.ch/wp-content/uploads/ ICC2011_SwissAtlasPlatform.pdf

[3] Federal Ministry for the Environment, Nature Conservation and Nuclear Safety. (2003). Hydrological Atlas of Germany. Retrieved from http://www.hydrology.unifreiburg.de/forsch/had/had_home.htm

[4] Hydrological Atlas of Switzerland. (2010). Printed issue Introduction to the Atlas. Retrieved from http://www.hydrologischeratlas.ch/en/products/printedissue

[5] Busskamp, R. \& Liebscher, H. J. (1997). Access to hydrological data from GIS applications by graphical software tools - an example from the Hydrological Atlas of Germany (HAD). Retrieved from http://hydrologie.org/ redbooks/a242/iahs_242_0255.pdf

[6] Kriz, K. \& Fürst, J. (2003). Cartographic Design Issues within the Hydrological Atlas of Austria. Proceedings of the $21^{\text {st }}$ International Cartographic Conference. Durban, 11311137. Retrieved from http://icaci.org/files/documents/ ICC_proceedings/ICC2003/Papers/442.pdf

[7] Struckmeier, W. F. \& Margat, J. (1995). Hydrogeological Maps, A Guide and a Standard Legend. Hannover. Retrieved from https://www.bgr.bund.de/EN/Themen/Wasser/ Projekte/laufend/Beratung/Ihme1500/standard_legend_hydr o_maps.pdf?_blob=publicationFile \& $\mathrm{v}=2$

[8] Federal Institute for Geosciences and Natural Resources. (2005). The $1: 5$ Million International Geological Map of Europe and Adjacent Areas. IGME 5000: More than just a map - A multinational GIS Project. Retrieved from https:/www.bgr.bund.de/EN/Themen/Sammlungen-

Grundlagen/GG_geol_Info/Karten/International/Europa/IG ME5000/IGME_Project/IGME_Projectinfo.html?nn=15563 88

[9] United Nations Educational, Scientific and Cultural Organization. (2009). Atlas of Transboundary Aquifers. UNESCO - IHP ISARM Programme. Retrieved from http://unesdoc.unesco.org/images/0019/001921/192145e.pd f

[10] International Hydrographic Organization. (2003). User's Handbook on Datum Transformations Involving WGS 84. Special IHO Publication No. 60 ( ${ }^{\text {rd }}$ ed.). Monaco: Author.

[11] Sretenović, B. LJ. (1976). Notion and Conception of the Spatiosystemic Atlas. Bulletin de la Societe Serbe de Geographie, 56(2), 89-96. Retrieved from http://www.digitalna.nb.rs/wb/NBS/casopisi_pretrazivi_po datumu/glasnik_srpskog_geografskog_drustva/1976/b056\# page/119/mode/1up

[12] Intergraph Corporation. (2004). Working with GeoMedia Professional. Intergraph Mapping and Geospatial Solution, Technical Documentation. Alabama, USA: Author.

[13] The Consultative Group for International Agriculture Research - Consortium for Spatial Information. (2014). Shuttle Radar Topography Mission (SRTM) 90m Digital Elevation Data. Retrieved from http://srtm.csi.cgiar.org/ index.asp and from http://srtm.csi.cgiar.org/SELECTION/ inputCoord.asp

[14] United States Geological Survey. (2014). Shuttle Radar Topography Mission - SRTM. Retrieved from https://lta.cr.usgs.gov/SRTM

[15] Jet Propulsion Laboratory - California Institute of Technology. (2011). The Advanced Spaceborne Thermal Emission and Reflection Radiometer-Global Digital 
Elevation Model (ASTER GDEM). Retrieved from https://asterweb.jpl.nasa.gov/gdem.asp

[16] United States Geological Survey. (2014). Global Topographic 30 Arc Second Elevation Data - GTOPO30. Retrieved from https://ta.cr.usgs.gov/GTOPO30

[17] United States Geological Survey. (2014c). HYDRO1K. Retrieved from https://ta.cr.usgs.gov/HYDRO1K

[18] Military Geographical Institute. (1987). International Map of the World 1:1000 000. Belgrade, Serbia: Author.

[19] Borisov, M. (1996). General Geographic Map of FR Yugoslavia 1:1000 000 (Master's thesis). Faculty of Civil Engineering, University of Belgrade, Serbia.

[20] Federal Institute for Geosciences and Natural Resources. (2014). IHME1500 - International Hydrogeological Map of Europe $\quad 1: 1500000$. Retrieved from https://www.bgr.bund.de/EN/Themen/Wasser/Projekte/lauf end/Beratung/Ihme1500/ihme1500_projektbeschr_en.html

[21] The Consultative Group for International Agriculture Research - Consortium for Spatial Information. (2008). SRTM 90m Digital Elevation Database v4.1. Retrieved from http://www.cgiar-csi.org/data/srtm-90m-digital-elevationdatabase-v4-1

[22] Reuter, H. I., Nelson, A., \& Jarvis, A. (2007). An Evaluation of Void Filling Interpolation Methods for SRTM Data. International Journal of Geographic Information Science, 21(9), 983 - 1008. Retrieved from http://www.cgiarcsi.org/wp-content/blogs.dir/5/images/ stories/docs/Reuteretal2007.pdf https://doi.org/10.1080/13658810601169899

[23] Stamenković, N., Šoškić, S., Kostić, M., Gigović, Lj., Regodić, M., \&Bakrač, S. (2017). Modelling of thematic digital atlas of the Bokakotorska gulf within geographic information system. Technical Gazette, 24(5), 1627-1634. https://doi.org/10.17559/TV-20151020214813

\section{Contact information:}

\section{Nikola STAMENKOVIĆ, PhD}

Ministarstvo odbrane

UI. Nemanjina 15, 11000 Beograd, Serbia

E-mail: stnikola2@yahoo.com

\section{Saša BAKRAČ, PhD}

Ministarstvo odbrane, Vojnogeografski institut

UI. Mije Kovačevića 5, 11000 Beograd, Serbia

E-mail: sbakrac@yahoo.com

\section{Miodrag KOSTIĆ, PhD}

Ministarstvo odbrane

UI. Nemanjina 15, 11000 Beograd, Serbia

E-mail: kmiodrag@ikomline.net

\section{Svetislav ŠOŠKIĆ, PhD}

Ministarstvo odbrane, Vojna akademija

UI. Generala Pavla Jurišića Šturma 33, 11000 Beograd, Serbia

E-mail: cacaksole@yahoo.com

\section{Zoran SRDIĆ, PhD}

Ministarstvo odbrane, Vojnogeografski institut

UI. Mije Kovačevića 5, 11000 Beograd, Serbia

E-mail: zoran.srdic@vs.rs 